\title{
DETECÇÃO DE DOENÇAS TRANSMISSÍVEIS EM GESTANTES NO ESTADO DE GOIÁS: O TESTE DA MAMÃE
}

\section{Clidenor Gomes Filho ${ }^{1}$, José Vicente Macedo Filho², Ana Lúcia Minuzzi², Mariana Mesquita Gomes ${ }^{3}$ e Alejandro Ostermayer Luquetti ${ }^{4}$}

\section{RESUMO}

Neste trabalho é descrita a triagem de doenças infecciosas em gestantes do estado de Goiás para detecção de agravos que podem ser transmitidos durante a gravidez e causar sequelas na criança. A triagem é realizada por meio de programa da Secretaria Estadual da Saúde em parceria com a Associação de Pais e Amigos dos Excepcionais (APAE) e as Secretarias Municipais de Saúde. A experiência da APAE na detecção de algumas doenças congênitas por teste simples em papel filtro foi aproveitada e seu uso expandido para a detecção de doenças infecciosas/transmissíveis. De setembro de 2003 até junho de 2009 foram examinadas amostras de 348.037 gestantes. Implantada progressivamente a partir de dois municípios, a triagem para doenças infecciosas está disponível em 245 dos 246 municípios do estado de Goiás. Os agravos triados foram: sífilis, HIV/Aids, toxoplasmose, rubéola, hepatites B e C, infecção pelo Trypanosoma cruzi, HTLV e citomegalovirose. A triagem foi realizada em papel filtro por testes imunoenzimáticos (ELISA) para cada marcador e os resultados positivos foram confirmados por coleta de sangue venoso, cujo soro foi encaminhado a diferentes centros de referência. Foram identificadas 11.061 gestantes com resultados positivos. A confirmação após os testes com soro foi obtida em $10.496(94,9 \%)$ amostras com as seguintes prevalências: sífilis: $4.028(1,2 \%)$; toxoplasmose: $2.320(0,7 \%)$, anticorpos anti-T. cruzi: 1.768 (0,5\%); hepatite B: 956 (0,3\%); HIV: 469 (0,1\%), hepatite C: 334 (0,1\%), HTLV: 312 $(0,1 \%)$, rubéola: $181(0,05 \%)$ e fase aguda de citomegalovirose: $128(0,04 \%)$. Os resultados foram encaminhados ao pré-natalista e ao núcleo de vigilância epidemiológica municipal.

DESCRITORES: Gestação; doenças transmissíveis; prevenção; triagem; pré-natal.

\section{ABSTRACT}

Detection of transmissible diseases in pregnant women in the State of Goias, Brazil. Maternal screening.

\footnotetext{
1. Secretaria Estadual De Saúde De Goiás, Goiânia, Brasil.

2. Associação de Pais e Amigos dos Excepcionais de Goiânia (APAE-Goiânia), Goiânia, Brasil.

3. Escola Superior De Ciências Da Saúde, Brasília, DF e Ela Diagnósticos, Goiânia, Brasil.

4. Departamento de Microbiologia, Imunologia, Parasitologia e Patologia do Instituto de Patologia Tropical e Saúde Pública, Universidade Federal de Goiás, Goiânia, Brasil.
} 
This paper describes the screening of some infectious diseases in pregnant women that may be transmissible and harmful to their infants. The screening was performed as an Official State Public Health Program from the Secretary of Health in the State of Goias, Brazil, with the aid of the "Parents and Friends of the Handicapped Association" (APAE), a non-profitable organization also responsible for the Program for Congenital diseases in Newborns. The tests are performed using filter paper and the screening described here is called the "Mother's Test". From September 2003 until June 2009, 348,037 women were tested. This program involves nearly all the municipalities in the State. Immunoenzimatic (ELISA) tests were performed for syphilis, HIV/Aids, toxoplasmosis, rubella, hepatitis B and C, infection by Trypanosoma cruzi, HTLV and Citomegalovirus (CMV). Positive results $(\mathrm{n}=11,061)$ were confirmed later by venous blood collection. The confirmation of a positive result was obtained in $94.9 \%$ ( $\mathrm{n}=10,496$ serum samples), where 4,028 were syphilis $(1.2 \%) ; 2,320$ toxoplasmosis $(0.7 \%)$; 1,768 Chagas disease $(0.5 \%)$; 956 hepatitis $\mathrm{B}(0.3 \%)$; $469 \mathrm{HIV}(0.1 \%)$; 334 hepatitis $\mathrm{C}(0.1 \%)$; $312, \operatorname{HTLV}(0.1 \%) ; 181(0.05 \%)$ rubella and 128 in the acute stage of $\operatorname{CMV}(0.04 \%)$. Final results were sent to the patients' physicians and the Epidemiological Surveillance authorities of the Municipality.

KEY WORDS: Gestation; transmissible disease; prevention; screening; antenatal exame.

\section{INTRODUÇÃO}

Está bem demonstrado que uma atenção pré-natal de qualidade é fundamental para a saúde tanto materna quanto neonatal (Brasil, 2006).

Embora a quantidade de consultas de pré-natal para cada gestante tenha tido um incremento significativo nos últimos anos, o impacto sobre os indicadores de saúde materna e infantil tem sido menor que o esperado (Gomes-Filho \& Gomes, 2007). Especula-se que este impacto reduzido se deve a fatores relacionados à qualidade do pré-natal (Gomes-Filho et al, 2002; Viellas et al., 2014).

Uma das deficiências mais significativas que influenciam a qualidade do pré-natal é a dificuldade que as gestantes encontram para realizar os exames laboratoriais. Esta dificuldade de acesso tem características próprias em cada região. Em Goiás, apenas 82 dos 246 municípios contam com laboratórios clínicos. Este é um dos fatores que fazem com que muitas gestantes cheguem ao final do pré-natal sem ter realizado os testes laboratoriais necessários.

Em virtude da importância de algumas doenças genéticas e do fato de que uma deteç̧ão precoce pode minimizar seus efeitos, foram estabelecidos programas para sua deteç̧ão em vários países do mundo (Guthrie \& Susi, 1963; Pollitt et al., 1997; Simpson et al., 1997; Pass et al., 2000; Kurinczuk et al., 2002; Jones et al., 2006; Farrioux et al., 2003; Borrajo, 2007; Loeber, 2007;), incluindo o Brasil (La Franchi, 1995; Franco et al., 1997; Ramos et al., 2003; Nascimento et al., 2003; Ramalho et al., 2004).

As Associações de Pais e Amigos dos Excepcionais (APAE) têm consolidado uma grande experiência na triagem neonatal no País utilizando a coleta de sangue periférico em papel filtro. A ampla cobertura e a qualidade do serviço têm sido reconhecidas como importante contribuição para a prevenção de transmissão vertical de doenças genéticas (Carvalho et al., 2007). 
Esta tecnologia já está disponível para diagnóstico de doenças infecciosas que podem ser transmitidas da gestante para o feto (Reiche et al., 2000; Zufiarre et al., 2004; Figueiró-Filho et al., 2007; Botelho et al., 2008; Lima \& Viana 2009; Figueiredo et al., 2009).

A dificuldade de acesso aos testes laboratoriais tradicionais e a disponibilidade das novas tecnologias criaram uma janela de oportunidades que pode levar à melhora da qualidade do pré-natal.

Neste contexto, a APAE Goiânia apresentou, no ano de 2002, às secretarias municipais de saúde de Goiânia e de outros municípios do estado de Goiás e, depois, à Secretaria Estadual de Saúde de Goiás um projeto de parceria que resultou no Programa de Proteção à Gestante de Goiás. Iniciativa semelhante estava em curso desde 2002 no Mato Grosso do Sul, com bons resultados (Figueiró-Filho et al., 2007; Botelho et al., 2008). Para fazer analogia com a triagem neonatal (Teste do Pezinho), o programa recebeu a marca "Teste da Mamãe" e está em execução no estado de Goiás desde setembro de 2003.

O objetivo deste trabalho foi descrever o programa e mensurar a magnitude dos diferentes agravos triados como forma de contribuir para a formulação de políticas de saúde pública.

\section{MATERIAL E MÉTODOS}

Trata-se de estudo retrospectivo, realizado no estado de Goiás, no período de setembro de 2003 a junho de 2009, compreendendo amostras em papel filtro de 348.037 gestantes, residentes em 245 municípios do estado. Foram incluídas todas as gestantes que consultaram para o exame prénatal. Depois de preenchida, a ficha- padrão e também as amostras foram encaminhadas a um único centro em Goiânia (Instituto de Diagnóstico e Prevenção da APAE Goiânia -IDP APAE Goiânia), que realizou os testes de triagem correspondentes (ver fluxograma, Figura 1). Para aquelas amostras com resultado positivo, foi solicitada uma nova amostra, agora de sangue venoso, encaminhada ao IDP APAE Goiânia, que, além da repetição dos testes, encaminhou os respectivos soros a dois centros de referência. $\mathrm{O}$ banco de dados foi alimentado com os dados constantes na ficha-padrão que incluíam, além de nome, data de nascimento, data de última menstruação, tempo de gestação, número de gestações, abortos e partos anteriores, município de origem e número de inscrição no Sistema de Informação do Pré-natal (SIS pré-natal). 


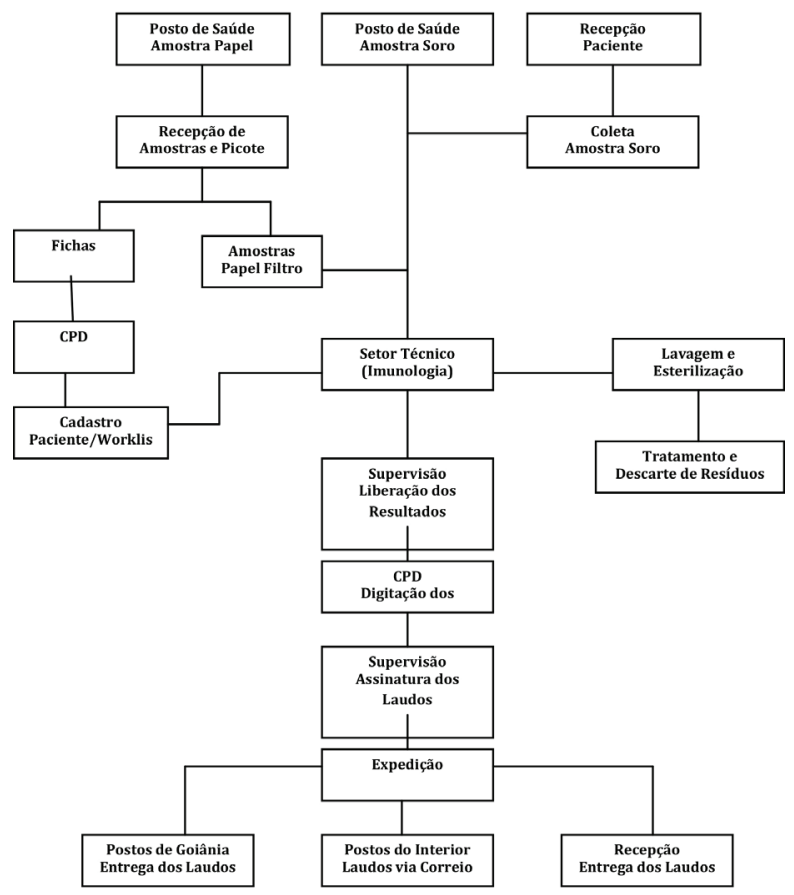

Figura 1. Fluxograma das amostras em papel-filtro das gestantes no Instituto de Diagnóstico e Prevenção, APAE, Goiânia.

\section{Teste da Mamãe}

Neste se encontram incluídos os seguintes testes para triagem de doenças infecciosas: virais: hepatite $\mathrm{B}$ ( $\mathrm{Ag} \mathrm{HBs}$ e $\mathrm{Ac}$ anti-HBc), hepatite $\mathrm{C}$ (Ac anti-HCV), HIV (Ac anti-HIV 1 e 2), rubéola (Ac anti-IgG e Ac anti-IgM), HTLV (Ac anti-HTLV 1e 2) e CMV (Ac anti-IgG e Ac anti- IgM); bacterianas: sífilis (Ac anti-Ig total); protozoários: toxoplasmose (deteç̧ão de anticorpos da classe IgG e IgM anti-Toxoplasma gondii) e infecção pelo Trypanosoma cruzi (detecção de anticorpos da classe IgG anti-T. cruzi).

\section{Triagem em papel filtro}

A triagem é realizada por meio da coleta de seis gotas de sangue periférico em papel filtro por ocasião da primeira consulta pré-natal. Não é necessário jejum da gestante, que deve autorizar, por escrito, a realização dos exames para atender à legislação e à necessidade do consentimento informado. $\mathrm{O}$ papel filtro utilizado é Schleicher \& Schuell 903® (Merck, Rio de Janeiro), o mesmo que é usado no Teste do Pezinho. 
O processamento das amostras é realizado no Instituto de Diagnóstico e Prevenção (IDP) da APAE em Goiânia (IDP, APAE), que encaminha o material necessário às diferentes unidades de pré-natal do estado de Goiás. Na chegada das amostras, cada uma é identificada com número de registro único e os dados da ficha padrão.

A amostra coletada permanece em temperatura ambiente por duas horas para secagem e depois é enviada pelos correios em envelope pré-pago, sem refrigeração, para o IDP da APAE em Goiânia. O tempo médio entre a coleta e a chegada ao laboratório é de 72 horas, com tolerância de até sete dias. No laboratório, a amostra é submetida a processo de eluição e analisada em equipamentos informatizados de elevada sensibilidade.

\section{Testes sorológicos utilizados}

A técnica utilizada para todos os marcadores é o teste imunoenzimático (Enzima-imunoensaio ELISA). Os conjuntos diagnósticos (kits) utilizados são: Diasorin ${ }^{\circledR}$ (São Paulo) para o agravo hepatite B; Adaltis ${ }^{\circledR}$ (Curitiba) para os agravos HTLV, HCV e sífilis; Radim ${ }^{\circledR}$ (São Paulo) para os agravos rubéola, citomegalovírus e toxoplasmose; Tecnosuma ${ }^{\circledR}$ (Belo Horizonte) para os agravos HIV e hepatite B; Omega ${ }^{\circledR}$ (São Paulo) para a infecção pelo Trypanosoma cruzi; Q-Preven ${ }^{\circledR}$ (São Paulo) para os agravos sífilis, HIV, toxoplasmose, rubéola e citomegalovírus; Murex (Abbott) ${ }^{\circledR}$ (São Paulo) para o agravo HTLV. Cada teste é executado conforme as instruções técnicas dos respectivos fabricantes.

\section{Testes confirmatórios}

Todos os resultados positivos são submetidos a exames confirmatórios por meio de coleta de sangue venoso. Para isso, funcionários do IDP APAE encaminham um kit composto de tubo de coleta de $5 \mathrm{~mL}$ (vacutainer ${ }^{\circledR}$ ) préidentificado com o número de identificação gerado pelo IDP (código de barras) e nome da gestante para a unidade de pré-natal do município em questão.

Uma vez localizada a gestante, é realizada a coleta de sangue venoso e o encaminhamento é feito via SEDEX em caixa de isopor a $4^{\circ} \mathrm{C}$, contendo gelo reciclável (gelopac), para o IDP da APAE em Goiânia. O tempo médio de chegada das amostras de sangue é de 24 horas com limite de 36 horas. O soro é separado em três alíquotas, sendo uma delas para repetição dos testes no IDP, outra para estoque e a terceira encaminhada aos laboratórios de referência.

Como testes confirmatórios foram incluídos os seguintes: hepatite B: Ag HBs (ELISA), PCR, Ag HBe (ELISA), Anti-HBe (ELISA) e Anti-HBs (ELISA); hepatite C: Ac Anti-HCV (ELISA), PCR, IMUNOBLOT; HIV: Ac Anti-HIV 1 e 2 (ELISA), PCR e Western Blot; rubéola: Ac IgG (ELISA) e Ac IgM (ELISA), Teste de Avidez de IgG (ELISA); HTLV: Ac Anti HTLV 1 e 2 (ELISA), PCR e 
Western Blot; CMV: Ac Anti-IgG e Ac Anti IgM (ELISA), Teste de avidez de IgG (ELISA); bacterianas: sífilis: Ac Anti-Ig total (ELISA), VDRL e FTA-Abs IgG (IFI); protozoários: toxoplasmose: Ac Anti-IgG e Ac Anti-IgM (ELISA), Teste de avidez de IgG (ELISA) e infecção pelo T. cruzi: ELISA (Bioschile ${ }^{\circledR}$ ), imunofluorescência indireta (antígeno in house, conjugado Biomerieux ${ }^{\circledR}$ antiIgG humana) e hemaglutinação indireta (Wiener $\left.{ }^{\circledR}\right)$.

As amostras de soro com suspeita de mãe infectada com T. cruzi são encaminhadas ao laboratório de pesquisa em doença de Chagas da Universidade Federal de Goiás, enquanto as demais são encaminhadas ao Laboratório Central de Saúde Pública do Estado de Goiás (LACEN), referência para os outros agravos. Os laboratórios especializados encaminham ao IDP os resultados confirmatórios em prazos de 7 a 15 dias e este encaminha ao pré-natalista de cada município.

Os resultados positivos somente são entregues à gestante, com cópia para o serviço de pré-natal, depois da confirmação. O tempo médio para todo o processo é de três semanas, permitindo que os resultados estejam disponíveis para a próxima consulta pré-natal. O serviço produz também relatórios específicos para a vigilância epidemiológica e para as áreas técnicas de saúde da mulher das Secretarias de Saúde.

Os testes realizados mensuram infecção na fase aguda ou recente (Ac anti [agente] da clase IgM) e infecção pregressa (Ac anti [agente] da classe $\operatorname{IgG})$.

\section{RESULTADOS}

\section{Cobertura do Programa em municípios do Estado de Goiás 2003-2009}

Entre setembro de 2003 e junho de 2009, 348.037 gestantes foram beneficiadas pelo programa em 245 municípios do estado de Goiás (99,3\% dos municípios) de forma gratuita, com financiamento do Sistema Único de Saúde (SUS).

A Figura 2 mostra o número de municípios atendidos ao longo do período, sendo possível que todas as gestantes do estado de Goiás se beneficiem do programa. 


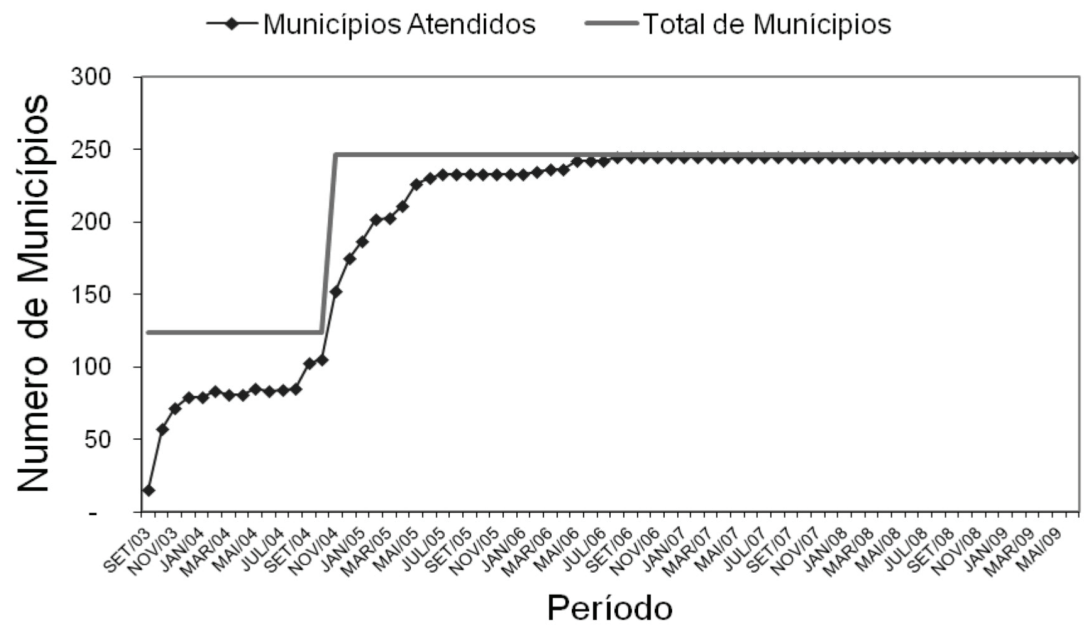

Figura 2. Número mensal dos municípios participantes do Programa de Proteção à Gestante em Goiás, durante o período de setembro de 2003 a julho de 2009.

Fonte: Instituto de Diagnóstico e Prevenção, APAE, Goiânia.

A Figura 3 mostra a cobertura do programa no mesmo período, segundo o número de gestantes atendidas.

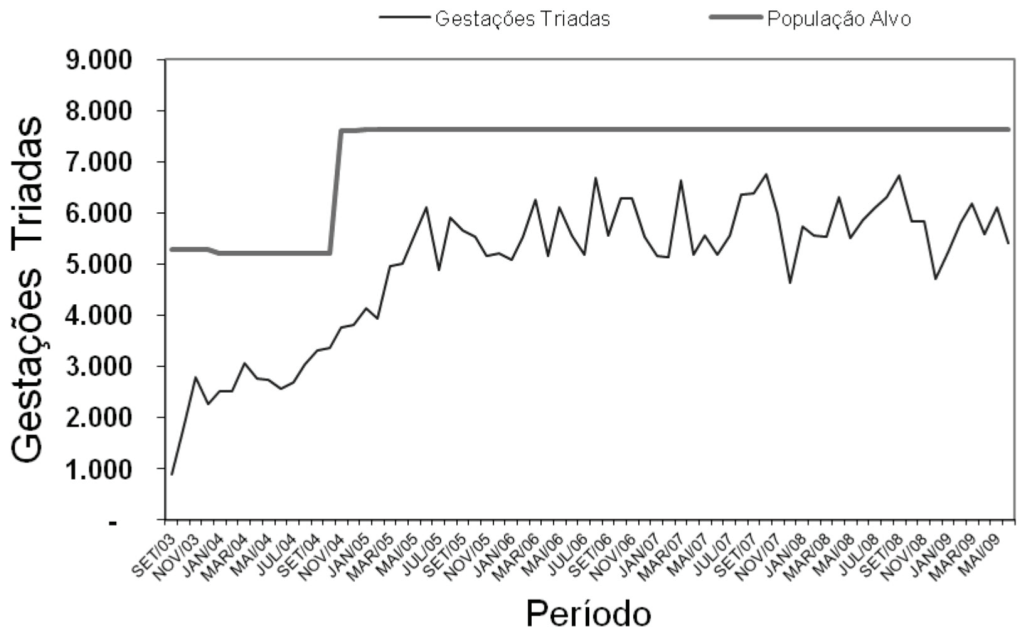

Figura 3. Número de mulheres triadas pelo Programa de Proteção à Gestante em Goiás, por mês, durante o período de 2003-2009.

Fonte: Instituto de Diagnóstico e Prevenção, APAE, Goiânia 
2. Descrição da população, faixa etária e idade gestacional no diagnóstico.

As gestantes cobertas pelo programa são mulheres em idade fértil ( 10 a 49 anos). Observou-se que $3.835(1,1 \%)$ tinham até 14 anos de idade e $81.182(23,3 \%)$ tinham 15 a 19 anos, o que é compatível com o número de adolescentes que deram à luz a nascidos vivos em Goiás no período, segundo dados consolidados pelo Sistema Nacional de Nascidos Vivos e disponíveis no sítio de internet do DATASUS. A maior frequência de casos (243.452 gestantes, que correspondem a 69,9\%) estava na faixa etária ideal para a gravidez ( $>17$ e $<35$ anos (Schirmer et al., 2000) e 15.297 $(4,4 \%)$ encontravam-se acima de 35 anos. A distribuição é também compatível com as estatísticas do DATASUS para nascidos vivos (Tabela 1).

Tabela 1. Distribuição das gestantes triadas segundo a faixa etária, Goiás, 2003-2009 e comparação com a distribuição de nascidos vivos segundo a faixa etária da mãe, Goiás, DATASUS 2004-2008.

\begin{tabular}{lcccc}
\hline \multicolumn{1}{c}{ FAIXA } & & & & \\
ETÁRIA & No. GEST. & FREQ. & No. N. VIV. & $\%$ COBERTURA \\
\hline Até 14 anos & 3.835 & $1,1 \%$ & 401.600 & $95,5 \%$ \\
$15-19$ & 81.182 & $23,3 \%$ & 93.706 & $86,6 \%$ \\
$20-35$ & 243.452 & $69,9 \%$ & 315.853 & $77,1 \%$ \\
36 ou mais & 15.297 & $4,4 \%$ & 28.884 & $53,0 \%$ \\
Não informado & 4.271 & $1,2 \%$ & 432 & - \\
TOTAL & 348.037 & $100,0 \%$ & 442.891 & $78,6 \%$ \\
\hline
\end{tabular}

Legenda: No.Gest.: Número de gestantes. Freq.: frequência. No. N.VIV.: Número de nascidos vivos segundo a faixa etária da mãe, Goiás, 2004-2008, dados de DATASUS. \% Cobertura: percentagem de cobertura deste estudo em relação com os dados de nascidos vivos segundo DATASUS.

Fontes: Instituto de Diagnóstico e Prevenção, APAE, Goiânia e DATASUS.

Quanto ao período gestacional por ocasião da primeira coleta de sangue em papel filtro, concluiu-se que quase a metade $(48,4 \%)$ foi feita no primeiro trimestre. Os registros não apresentavam a idade gestacional em 16,8\% dos casos (Tabela 2).

Cabe destacar que $14,9 \%$ das gestantes relataram ocorrência de abortamento anterior, conforme está demonstrado na Tabela 3. 
Tabela 2. Distribuição das gestantes triadas, segundo o período gestacional, Goiás, 2003-2009.

\begin{tabular}{lcc}
\multicolumn{1}{c}{ PERÍODO } & No. DE GESTANTES & FREQUÊNCIA \\
\hline Até 12 semanas & 168.429 & $48,4 \%$ \\
13 a 24 semanas & 108.574 & $31,2 \%$ \\
25 a 36 semanas & 11.072 & $3,2 \%$ \\
37 semanas ou mais & 1.400 & $0,4 \%$ \\
Não informado & 58.562 & $16,8 \%$ \\
TOTAL & 348.037 & $100,0 \%$ \\
\hline
\end{tabular}

Fonte: Instituto de Diagnóstico e Prevenção, APAE, Goiânia.

Tabela 3. Distribuição das gestantes triadas, segundo antecedentes de abortamento, Goiás, 2003-2009.

\begin{tabular}{lccc}
\hline \multicolumn{1}{c}{ NO. DE } & No. DE GESTANTES & \% DO TOTAL & FREQUÊNCIA \\
\hline 1 & 41.412 & $11,9 \%$ & $79,7 \%$ \\
2 & 7.882 & $2,3 \%$ & $15,2 \%$ \\
3 & 1.828 & $0,5 \%$ & $3,5 \%$ \\
$\geq 4$ & 834 & $0,2 \%$ & $1,6 \%$ \\
TOTAL & 51.956 & $14,9 \%$ & $100,0 \%$ \\
\hline
\end{tabular}

Fonte: Instituto de Diagnóstico e Prevenção, APAE, Goiânia.

3. Resultados de acordo com os diferentes agravos.

Na Tabela 4, encontra-se a frequência de cada agravo, incluindo os resultados confirmados após coleta em sangue venoso. Houve confirmação em, aproximadamente, $90 \%$ dos resultados positivos inicialmente detectados em papel filtro (de $89 \%$ para HIV a $99 \%$ naqueles que indicavam toxoplasmose). A prevalência foi maior para sífilis $(1,16 \%)$, toxoplasmose $(0,67 \%)$ e infecção pelo T. cruzi $(0,51 \%)$.

A Figura 4 mostra o número de agravos infecciosos confirmados pelo programa. Nas 348.037 gestantes atendidas foram confirmados 4.028 resultados de sífilis, 2.320 de toxoplasmose, 1.768 gestações em portadoras de doença de Chagas, 956 de hepatite B e 334 de hepatite C, 469 resultados de HIV/IDS, 312 de HTLV, 181 de rubéola e 128 de fase aguda de citomegalovirose. 
Tabela 4. Frequência de positividade aos diferentes agravos infecciosos no total de 348.037 gestantes triadas pelo Programa de Proteção à Gestante, Goiás, 2003-2009.

\begin{tabular}{lccccc}
\hline AGRAVO & TRIADOS & $\begin{array}{c}\text { RESULT. } \\
\text { POSITIVOS } \\
\text { PAPEL-FIL. }\end{array}$ & $\begin{array}{c}\text { RESULT. } \\
\text { CONFIRM. } \\
\text { EM SORO }\end{array}$ & $\%$ CO & PREVALENCIA \% \\
\hline Síflis & 348.037 & 4.278 & 4.028 & $94,2 \%$ & $1,16 \%$ \\
Toxoplasm. & 348.037 & 2.347 & 2.320 & $98,9 \%$ & $0,67 \%$ \\
D. Chagas & 348.037 & 1.856 & 1.768 & $95,3 \%$ & $0,51 \%$ \\
Hepatite B & 348.037 & 1.047 & 956 & $91,3 \%$ & $0,27 \%$ \\
HIV & 348.037 & 526 & 469 & $89,2 \%$ & $0,13 \%$ \\
Hepatite C & 348.037 & 349 & 334 & $95,7 \%$ & $0,10 \%$ \\
HTLV & 348.037 & 334 & 312 & $93,4 \%$ & $0,09 \%$ \\
Rubéola & 348.037 & 187 & 181 & $96,8 \%$ & $0,05 \%$ \\
CMV & 348.037 & 137 & 128 & $93,4 \%$ & $0,04 \%$ \\
TOTAL & 348.037 & 11.061 & 10.496 & $94,9 \%$ & $3,02 \%$ \\
\hline
\end{tabular}

Legenda: Triados: total de amostras em papel-filtro inicialmente triadas. Result.Positivos Papelfil: resultados em papel-filtro positivos. Result.confirm. em soro: resultados confirmados após coleta de soro. \% CO: percentagem de confirmados em soro, em relação aqueles com resultado positivo em papel-filtro. Prevalência \%: prevalência de cada agravo após confirmação. HIV: anticorpos anti-Human Immunodeficiency Virus (Vírus da imunodeficiência humana). HTLV: anticorpos anti-Human T-cell Lymphotropic Virus type I/II (vírus linfotrópico de células T humanas). CMV: anticorpos anti-citomegalovirus.

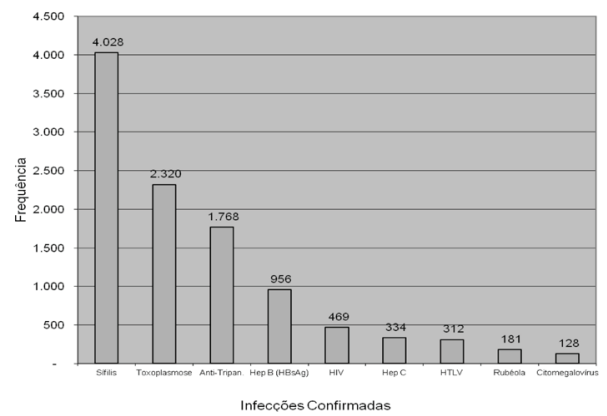

Figura 4. Frequência de agravos infecciosos confirmados pelo Programa de Proteção à Gestante, Goiás, 2003-2009.

Fonte: Instituto de Diagnóstico e Prevenção - APAE Goiânia.

Anti-Tripan.: confirmação de infecção pelo Trypanosoma cruzi. Hep.B: hepatite B. HIV: Vírus da imunodeficiência humana. Hep.C: confirmações de resultados para hepatite C. HTLV: human T lymphotropic virus. 
De acordo com a Tabela 4 , sífilis foi o agravo mais frequente na triagem, com 4.278 resultados positivos, sendo que $94 \%$ deles foram confirmados após a segunda coleta, de sangue venoso.

A toxoplasmose foi o segundo agravo mais prevalente, com 2.320 resultados positivos confirmados de infecção materna, seguida pela doença de Chagas, com 1.768 resultados confirmados após coleta de sangue venoso.

O valor preditivo positivo (VPP) e negativo (VPN) para cada agravo, se encontram na Tabela 5. Os cálculos para o VPP foram realizados em comparação com os resultados confirmados da coleta venosa. No entanto, perante a ausência de coleta venosa naqueles resultados negativos pelo papel de filtro, o cálculo do VPN foi obtido a partir de valores estimados para os casos negativos e falsopositivos por meio de cálculos com os valores de especificidade e sensibilidade do teste em papel de filtro, fornecidos pela APAE.

Tabela 5. Valor preditivo positivo (VPP) e valor preditivo negativo (VPN) para cada agravo infeccioso em gestantes triadas pelo Programa de Proteção à Gestante, Goiás, 2003-2009.

\begin{tabular}{lll}
\hline AGRAVO & VPP & VPN \\
\hline Sífilis & $94,2 \%$ & $91,0 \%$ \\
Toxoplasmose IgM & $98,9 \%$ & $99,6 \%$ \\
Toxoplasmose IgG & $98,9 \%$ & $99,1 \%$ \\
Doença de Chagas & $95,3 \%$ & $93,7 \%$ \\
HBS-Ag & $91,3 \%$ & $96,3 \%$ \\
Anti-HBcAg & $91,3 \%$ & $93,5 \%$ \\
HIV & $89,2 \%$ & $94,6 \%$ \\
Hepatite C & $95,7 \%$ & $99,3 \%$ \\
HTLV & $93,4 \%$ & $98,9 \%$ \\
Rubéola IgM & $96,8 \%$ & $99,9 \%$ \\
Rubéola IgG & $96,8 \%$ & $99,9 \%$ \\
CMV IgM & $93,4 \%$ & $99,8 \%$ \\
CMV IgG & $93,4 \%$ & $99,9 \%$ \\
\hline
\end{tabular}

VPP: calculado por comparação entre os resultados positivos em papel de filtro e os resultados obtidos em sangue venoso. VPN: obtido a partir de valores estimados para os resultados negativos em papel de filtro acrescidos dos falsos positivos em sangue venosa (negativos), por meio de cálculos com os valores de especificidade e sensibilidade de cada teste em papel de filtro, fornecidos pela APAE. 


\section{DISCUSSÃO}

Os resultados obtidos pela triagem de gestantes para doenças infecciosas por meio do Teste da Mamãe no estado de Goiás, no período estudado, apresentam várias características. A primeira refere-se ao sucesso obtido pela adesão da maioria dos municípios do estado. Isso só foi possível graças à estreita participação da Secretaria Estadual de Saúde do Estado e da APAE, como parte do Programa de Proteção à Gestante de Goiás. O antecedente de sucesso em programa similar no estado de Mato Grosso do Sul (Figueiró-Filho et al, 2007; Botelho et al. 2008) foi importante para concretizar esta parceria. O programa teve início em 2003 com projeto piloto em dois municípios, alcançando, em um ano, 245 municípios dos 246 existentes no estado de Goiás (99,6\%). Pelas características de gratuidade e efetividade, abrange a maioria das mulheres gestantes do estado e permite avaliar a prevalência dos principais agravos.

É importante ressaltar que este programa (Teste da Mamãe) não interfere nos exames do pré-natal. A tipagem sanguínea, o hemograma, a glicemia e o teste de urina continuam a ser realizados nos laboratórios tradicionais, o que foi considerado importante para não desorganizar as atividades dos serviços já disponíveis nos municípios.

Em segundo lugar, os resultados obtidos permitem estudar variáveis e relacionar a faixa etária, proporção de nascidos vivos, abortamento e comorbidades das gestantes no estado, o que possibilita medidas de prevenção.

Em terceiro lugar, a inclusão do papel filtro facilita a adesão das participantes no pré-natal e o fluxograma estabelecido pelo IDP APAE disponibiliza os resultados em poucas semanas. Observou-se também que metade das gestantes $(48,4 \%)$ foi submetida ao teste nas primeiras 12 semanas de gestação, o que permite o retorno do resultado de forma rápida. Se houver detecção de anticorpos para algum dos agravos testados, a confirmação pela coleta em sangue venoso permite ao médico, no campo, instituir medidas terapêuticas conforme o agravo. Quase um terço (31,2\%) das gestantes iniciaram o pré-natal entre 13 e 24 semanas.

Quanto às limitações deste estudo, ressalta-se a possibilidade de mais de uma entrada da mesma gestante em gestações sucessivas, facilitada pelo longo período de observação ( 5 anos e 10 meses). Em virtude da dimensão deste estudo, não foi possível identificar esta variável. Porém, em relação a um dos agravos (infecção pelo T. cruzi) que envolvia número menor de gestantes ( $\mathrm{n}=1.768$ ), foi possível estabelecer que, das primeiras 200 gestantes (até marco de 2005), 28 (14,0\%) foram detectadas em pelo menos duas gestações até o final do período estudado (junho de 2009). Este dado permite avaliar a efetividade do programa, uma vez que a mesma gestante foi detectada em duas oportunidades diferentes. 
Outra limitação relacionada à prevalência dos diferentes agravos no estado de Goiás diz respeito ao número de gestantes que não compareceram aos Postos de Saúde no pré-natal, a gestantes atendidas na rede privada ou que não fizeram o exame pré-natal. Acreditamos ser possível que a prevalência dessas infecções seja menor ou diferente, em particular para certos agravos como Aids, embora o real quantitativo não seja conhecido. Essas gestantes não triadas pelo programa podem explicar a discrepância observada na Tabela 1 em relação ao número de nascidos vivos, maior nas gestantes com faixas etárias maiores $(53 \%$ de cobertura em gestantes após os 35 anos de idade e $77 \%$ de cobertura em relação aos nascidos vivos de gestantes com idade entre 20 e 35 anos). Outra explicação parcial para essa divergência pode ser o número de abortos referidos (15\%) em gestações anteriores.

Este estudo demonstrou que, dos 348.037 testes realizados, apenas 11.061 resultados foram positivos $(3,2 \%)$. Pelo exposto, a maioria das gestantes no estado $(96,8)$, no período estudado, não apresentava anticorpos contra nenhum dos agravos testados. Este dado permite ao agente de saúde fazer o seguimento do pré-natal com bastante tranquilidade.

Em relação aos agravos encontrados, obteve-se sua confirmação em mais de $89 \%$ dos inicialmente positivos, dependendo do agravo. Isso demonstra a capacidade e efetividade do método em papel filtro de detecção das principais doenças infecciosas.

Assim como em outros estudos (Amaral et al., 1996; Figueiró-Filho et al., 2007; Botelho et al., 2008; Aboyeji \& Nwabuisis, 2003), alguns agravos foram mais frequentes, em particular sífilis $(1,16 \%)$, toxoplasmose $(0,67 \%)$ e doença de Chagas $(0,51 \%)$. Resultados similares são encontrados em população de doadores de sangue (Saéz-Alquezar et al., 2007) para sífilis e doença de Chagas. HIV/Aids, hepatite $\mathrm{B}$ e hepatite $\mathrm{C}$ foram confirmadas em percentagens similares $(0,27 \%$, $0,13 \%$, e $0,10 \%$ respectivamente). Em frequência menor, foram detectados HTLV, rubéola e citomegalovírus. Esses dados também refletem aqueles encontrados em Serviços de Hemoterapia para os marcadores HIV, hepatites e HTLV na população geral do Brasil.

Estudos em gestantes na Europa, como os de Zufiarre et al.(2004) sobre sífilis, toxoplasmose, rubéola, hepatite B e C e HIV na Espanha, referem prevalência menor que os estudos na América Latina.

O número de resultados positivos confirmados de sífilis é de grande importância epidemiológica em razão da natureza da doença, de suas graves sequelas em caso de transmissão para a criança, da possibilidade de cura na quase totalidade dos casos tratados ainda durante a gestação e, ainda, da possibilidade de controle da transmissão pelo tratamento do(s) parceiro(s) da mulher infectada. A prevalência encontrada foi de 1,16\%, enquanto Botelho et al.(2008) encontraram 2,6\% em Mato Grosso do Sul e Reiche et al. (2000) obtiveram 1,6\% em Londrina A possibilidade de controle da doença foi bem evidenciada por Macedo-Filho (2008), com redução progressiva e significativa da incidência de sífilis nos anos de 2005 a 2007. 
A toxoplasmose foi a segunda doença mais prevalente, com 2.320 resultados positivos confirmados de doença materna. $\mathrm{O}$ tratamento durante a gravidez pode reduzir significativamente os casos de contaminação fetal. Nos casos em que a criança já foi infectada, é possível a redução das sequelas pelo tratamento precoce do recém-nascido. Outra informação epidemiológica importante é a identificação de grávidas susceptíveis à doença (mulheres sem imunidade) e beneficiárias de prevenção pela adoção de hábitos higiênicos e dietéticos adequados. A prevalência encontrada foi de $0,6 \%$, maior que a obtida por Figueiró-Filho et al. (2005) em Mato Grosso do Sul (0,42\%).

A doença de Chagas é endêmica em Goiás. Mas o esforço dos serviços de saúde, que por décadas se dedicaram à erradicação dos insetos vetores (Silveira \& Dias, 2011), fez com que a transmissão vetorial fosse minimizada no estado (Luquetti et al, 2011). A confirmação de 1.708 gestantes portadoras da enfermidade surpreendeu os pesquisadores, pois não se esperava que houvesse ainda tantas mulheres infectadas em idade fértil. Embora o dado de naturalidade não esteja presente na ficha de cada grávida, constando apenas o município de residência, foi possível resgatar o dado da naturalidade daquelas gestantes que posteriormente compareceram à consulta médica $(\mathrm{n}=794)$, ficando evidenciadas migrações significativas, em particular de gestantes nascidas na Bahia $(56,3 \%)$ e residentes no estado de Goiás. A informação obtida nesses casos foi de 261 gestantes naturais do estado de Goiás (32,9\%), 447 da Bahia e 86 de outros estados. É importante lembrar que a doença de Chagas em recém-nascidos tem a possibilidade de cura na quase totalidade dos casos (Rassi et al., 2004; Luquetti et al., 2015). A prevalência encontrada foi de $0,5 \%$, maior que a obtida por Vaz et al. (1990) em São Paulo (0,3\%), o que se justifica por ser este último um estado não endêmico.

A confirmação de 956 resultados positivos de portadores de HBsAg e de 334 de hepatite $\mathrm{C}$ demonstra a importância epidemiológica destas doenças (Cardozo et al., 1996; Arraes et al., 2003; Lima \& Viana, 2009; Costa et al., 2009; Gardenal et al., 2011) que são graves em razão de suas consequências na saúde materna e ainda mais severas quando transmitidas para o recém-nascido. Embora não haja ainda cura, seus efeitos podem ser minimizados pelo adequado acompanhamento.

A identificação de 469 resultados positivos de gestantes com HIV/ AIDS (que corresponde a 1,5 casos por semana) permitiu que estas mulheres fossem incorporadas à rede de assistência e também que se beneficiassem da possibilidade de redução da transmissão vertical de $30 \%$ para apenas $2 \%$. A prevalência foi de $0,13 \%$. Resultados similares foram encontrados por Costa et al. (2009) em Goiânia no início deste programa. Na Nigéria, Offor et al. (2000) encontraram prevalência de $2,4 \%$ em gestantes, com transmissão vertical de $33,3 \%$.

A detecção de infecção pelo vírus HTLV, rubéola e citomegalovirose foi de menor prevalência, com um total de, respectivamente, 312,181 e 128 
resultados positivos confirmados. Estudos em diversos países já evidenciaram a importância destes marcadores na gravidez: Machuca et al. (2000) sobre HTLV na Espanha, Kashiwagi et al. (2004) no Japão, Olbrich Neto \& Meira (2004) e Bittencourt et al. (2001) no Brasil; Tookey et al. (2002) sobre rubéola em Londres; Spano et al. (2004) e Lazzarotto et al. (2004) sobre CMV. Embora sejam doenças de difícil condução clínica, sua identificação ainda na fase de gravidez é importante em razão da severidade das sequelas fetais, as quais podem ser atenuadas pelo adequado acompanhamento.

Além dos resultados objetivos na prevenção, tratamento e acompanhamento dos casos confirmados, dois outros resultados devem ser ressaltados.

O primeiro é a repercussão do programa sobre a organização dos serviços de pré-natal. Isso pode ser observado na melhora das informações epidemiológicas, no aumento da cobertura das consultas e na maior taxa de notificação dos agravos (dados não publicados da Secretaria de Saúde do Estado de Goiás observados por um dos autores [CGF]).

O segundo é o fato de que o programa tem contribuído para a melhor compreensão das doenças triadas. Cerca de duas dezenas de dissertações de mestrado (Siriano et al, 2011, Giffoni, 2009), de doutorado e trabalhos científicos (Luquetti et al., 2015) foram produzidos com base nos dados e nos conhecimentos acumulados no programa.

Os resultados até agora obtidos são consistentes o suficiente para ensejar a difusão do programa para outros estados e regiões, de forma que contribuam para a melhoria da assistência às gestantes e para a prevenção da transmissão vertical de doenças.

\section{AGRADECIMENTOS}

Os autores agradecem à Secretaria de Saúde do Estado de Goiás (SESGO), à Associação de Pais e Amigos dos Excepcionais de Goiânia (APAE-Goiânia) pela disponibilidade dos dados apresentados e ao Laboratório Central (LACEN) assim como ao Laboratório de Pesquisa da doença de Chagas pelos testes de confirmação realizados em soro e a Dra. Tatiana Haruka Sugita pela análise de valores preditivos.

\section{REFERÊNCIAS}

1. Aboyeji AP, Nwabuisis C. Prevalence of sexually transmitted diseases among pregnant women in Ilorin, Nigeria. J Obst Gynaecol 23: 637-639, 2003.

2. Amaral E, Faúndes A, Gonçales NSL, Pellegrino JJ, Souza CA, Silva JLP. Prevalence of HIV and Treponema pallidum infections in pregnant women in Campinas and their association with socio-demographic factors. São Paulo Medical Journal 114: 1108-1116, 1996.

3. Arraes LC, Sampaio AS, Barreto S, Guilherme MSA, Lorenzato F. Prevalência de hepatite B em parturientes e perfil sorológico perinatal. Rev Bras Ginecol Obstet 25: 571-576, 2003. 
4. Bittencourt AL, Dourado I, Filho PB, Santos M, Valadao E, Alcântara LC, Galvão-Castro B. Human T-cell lymphotropic virus type 1 infection among pregnant women in northeastern Brazil. J Acquired Immune Deficiency Syndrome 15: 490-494, 2001.

5. Brasil, Ministério da Saúde. Secretaria da Atenção à Saúde. Departamento de Ações Programáticas Estratégicas. Área Técnica de Saúde da Mulher. Pré-natal e puerpério: Atenção qualificada e humanizada. Manual técnico. Caderno 5. Brasília, 2006.

6. Borrajo GJ. Newborn screening in Latin America at the beginning of the 21 st century. $J$ Inherit Metab Dis 30: 466-481, 2007.

7. Botelho CAO, Tomaz CAB, Cunha RV, Botelho MAO, Botelho LO, Assis DM, Pinho DLM. Prevalência dos agravos triados no programa de proteção à gestante do Estado do Mato Grosso do Sul de 2004 a 2007. Rev Patol Trop 37: 341-353, 2008.

8. Cardozo DDP, Faria EL, Azevedo MSP, Queiroz DAO, Martins RMB, Souza TT, Daher RR, Martelli CMT. Soroepidemiologia para o vírus da hepatite B em gestantes/parturientes e sua transmissão para os recém nascidos em Goiânia, GO. Rev Soc Bras Med Trop 29: 349-353, 1996.

9. Carvalho TM, Santos HP, Santos IC, Vargas PR, Pedrosa J. Newborn screening: a national public health program in Brazil. J Inherit Metab Dis 30: 615, 2007.

10. Costa ZB, Machado GC, Avelino MM, Gomes-Filho C, Filho J, Minuzzi AL, Turchi MD, Stefani MMA, de Souza W, Martelli CMT. Prevalence and risk factors for Hepatitis C and HIV-1 infections among pregnant women in Central Brazil. BMC Infectious Diseases 9: 116125, 2009.

11. DATASUS (http://tabnet.datasus.gov.br/cgi/tabcgi.exe?sinasc/cnv/nvgo.def)Acesso: 9/4/2013.

12. Farriaux JP, Vidailhet M, Briard ML, Belot V, Dhondt JL. Neonatal screening for cystic fibrosis: France rises to the challenge. J Inherit Metab Dis 26: 729-744, 2003.

13. Figueiredo EN, Vianna LAC, Peixe MB, Ramos VM, Succi RCM. The challenge of the reference and counter-reference system in the prenatal assistance to pregnant women with infectious diseases. An Acad Bras Ciênc 81: 551-558, 2009.

14. Figueiró-Filho EA, Lopes AHA, Senefonte FRA, Souza JVG, Botelho CA, Figueiredo MS, Duarte G. Toxoplasmose aguda: estudo da freqüência, taxa de transmissão vertical e relação entre os testes diagnósticos materno-fetais em gestantes em estado da Região Centro-Oeste do Brasil. Rev Bras Ginecol Obstet 27: 442-449, 2005.

15. Figueiró-Filho EA, Senefonte FRA, Lopes AHA, Morais OO, Souza VGJ,Maia TL, Duarte G. Freqüência das infecções pelo HIV-1, rubéola, sífilis, toxoplasmose, citomegalovírus, herpes simples, hepatite B, hepatite C, doença de Chagas e HTLV I/II em gestantes, do Estado de Mato Grosso do Sul. Rev Soc Bras Med Trop 40: 181-187, 2007.

16. Franco DB, Maciel RBM, Matsumura LK, Kunii IS, Furuzawa GK; Faria AM, Vieira JGH. Implantação do programa de rastreamento do hipotireoidismo congênito na Fundação Hospitalar do Distrito Federal: metodologia, resultados, dificuldades e propostas: estudo comparativo com recém-natos de outros estados. Arq Bras Endocrinol Metab 41: 6-13, 1997.

17. Gardenal RVC, Figueiró-Filho EA, Luft JL, Paula GLSA, Vidal FG, Turine Neto P, Souza RAA. Hepatite C e gestação: análise de fatores associados à transmissão vertical. Rev Soc Bras Med Trop 44: 43-47, 2011.

18. Giffoni AA. Toxoplasmose em gestantes : abordagem epidemológica nos postos de saúde da rede pública da cidade de Rio Verde, Goiás. [Dissertação de Mestrado] 2009.

19. Gomes-Filho C, Gomes FM. Desigualdades sociais associadas à mortalidade materna. Arquivos Saúde Pública 7: 17-23, 2007.

20. Gomes-Filho C, Ramos CH, Paula DG, Carvalho L, Araújo L, Pacheco ME, Barreto MAG. Mortalidade materna e neonatal em Goiás (monografia). São Paulo: Faculdade de Saúde Pública, Universidade de São Paulo, 2002. 80 p. 
21. Guthrie R, Susi A. A simple phenylalanine method for detecting phenylketonuria in large populations of newborn infants. Pediatrics 32: 338-343, 1963.

22. Jones JH, Mackenzie J, Croft GA, Beaton S, Young D, Donaldson MD. Improvement in screening performance and diagnosis of congenital hypothyroidism in Scotland 1979-2003. Arch Dis Child 91: 680-685, 2006.

23. Kashiwagi K, Furusyo N, Nakashima H, Kubo N, Kinukawa N, Kashiwaqi S, Haiyashi J. A decrease in mother-to-child transmission of human T lymphotropic virus type I (HTLV-I) in Okinawa, Japan. Amer J Trop Med Hyg 70: 158-163, 2004.

24. Kurinczuk JJ, Bower C, Lewis B, Byrne G. Congenital hypothyroidism in Western Australia 1981-1998. J Paediatr Child Health 38: 187-191, 2002.

25. LaFranchi S. Detecção neonatal de hipotireoidismo congênito: uma história de sucesso? Arq Bras Endocrinol Metab 39: 80-88, 1995.

26. Lazzarotto T, Gabrielli L, Lanari M. Congenital cytomegalovirus infection: recent advances in the diagnosis of maternal infection. Humman Immunology 65: 410-452, 2004.

27. Lima LHM, Viana MC. Prevalence and risk factors for HIV, syphilis, hepatitis B, hepatitis $\mathrm{C}$, and HTLV-I/II infection in low-income postpartum and pregnant women in Greater Metropolitan Vitória, Espírito Santo State, Brazil. Cad Saúde Pública 25: 668-676, 2009.

28. Loeber JG. Neonatal screening in Europe; the situation in 2004. J Inherit Metab Dis 30: 430438, 2007.

29. Luquetti AO, Passos ADC, Silveira AC, Ferreira AW, Macedo V, Prata AR. O inquérito nacional de soroprevalência de avaliação do controle da doença de Chagas no Brasil (20012008). Rev. Soc Bras Med Trop 44 (Supl.2): 108-121, 2011.

30. Luquetti AO, Tavares SB, Siriano LR, de Oliveira RA, Campos DE, de Morais CA, de Oliveira EC. Congenital transmission of Trypanosoma cruzi in central Brazil. A study of 1,211 individuals born to infected mothers. Mem Inst Oswaldo Cruz 110: 369-376, 2015.

31. Macedo Filho JV. Redução da sifilis em gestantes - a experiência do programa de proteção a gestante do estado de Goiás. [Dissertação de Mestrado]. Universidade de Brasília, Brasília, 2008.

32. Machuca A, Tuset C, Soriano V, Caballero E, Aguilera A, Ortiz de Lejarazu R. Prevalence of HTLV infection in pregnant women in Spain. HTLV Spanish Study Group. Sexually Transmitted Infections 76: 366-370, 2000.

33. Nascimento ML, Pires MMS, Nassar SM, Ruhland L. Avaliação do programa de rastreamento neonatal para hipotireoidismo congênito da Secretaria de Estado da Saúde de Santa Catarina. Arq Bras Endocrinol Metab 47: 75-81, 2003.

34. Offor JUE, Onakewhor FE, Okonofua E. Maternal and neonatal seroprevalence of human immunodeficiency virus antibodies in Benin City, Nigeria. JObstetric Gynaecol 20: 589-599, 2000.

35. Olbrich Neto J, Meira DA. Soroprevalência de vírus linfotrópico de células T humanas, vírus da imunodeficiência humana, sífilis e toxoplasmose em gestantes de Botucatu, São Paulo, Brasil. Fatores de risco para vírus linfotrópico de células T humanas. Rev Soc Bras Med Trop 37: 28-32, 2004.

36. Pass KA, Lane PA, Fernhoff PM, Hinton CF, Panny SR, Parks JS, Pelias MZ, Rhead WJ, Ross SI,Wethers DL, Elsas LJ. US newborn screening system guidelines II: follow-up of children, diagnosis, management, and evaluation. Statement of the Council of Regional Networks for Genetic Services (CORN). J Pediatr 137(4 Suppl): S1-46, 2000.

37. Pollitt RJ, Green A, McCabe CJ, Booth A, Cooper NJ, Leonard JV, Nicholl J, Nicholson P, Tunaley JR, Virdi NK. Neonatal screening for inborn errors of metabolism: cost, yield and outcome. Health Technol Assess 1: 1-202, 1997.

38. Ramalho RJR, Ramalho ARO, Oliveira CRP, Aguiar-Oliveira MH. Evolução do programa de triagem neonatal para o hipotireoidismo congênito e fenilcetonúria no Estado de Sergipe de 1995 a 2003. Arq Bras Endocrinol Metab 48: 890-896, 2004. 
39. Ramos AJS, Rocha AM, Costa ADM, Benicio AVL, Ramos ALC, Silva CRA, Carvalho CR, Melo CLA. Avaliação do programa de rastreamento de doenças congênitas em Campina Grande-PB, Brasil. Arq Bras Endocrinol Metab 47: 280-284, 2003.

40. Rassi A, Amato Neto V, Rassi GG, Amato VS, Rassi Júnior A, Luquetti AO, Rassi SG. Busca retrospectiva da transmissão maternal da infecção chagásica em pacientes na fase crônica. Rev Soc Bras Med Trop 37: 485-489, 2004.

41. Reiche EMV, Morimoto HK, Farias GN, Hisatsugu KR, Geller L, Gomes ACLF, Inoue HY, Rodrigues G, Matsuo T. Prevalência de tripanossomíase americana, sífilis, toxoplasmose, rubéola, hepatite $\mathrm{B}$, hepatite $\mathrm{C}$ e da infecção pelo virus da imunodeficiência humana, avaliada por intermédio de testes sorológicos, em gestantes atendidas no período de 1996 a 1998 no hospital Universitário Regional Norte do Paraná (Universidade Estadual de Londrina, Paraná, Brasil). Rev Soc Bras Med Trop 33: 519-527, 2000.

42. Sáez-Alquézar A, Albieri D, Garrini RHC, Marques WP, Lemos EA, AlvesA. Desempenho de testes sorológicos para sífilis, treponêmicos (ELISA) e não treponêmicos (VDRL e RPR), na triagem sorológica para doadores de sangue-Confirmação dos resultados por meio de três testes treponêmicos (FTA ABS, WB e TPHA). Rev Patol Trop 36: 215-228, 2007.

43. Schirmer J. Assistência Pré-natal. Manual técnico. $3^{\mathrm{a}}$ edição, Brasília. Secretaria de Políticas de Saúde, Ministério da Saúde, 2000. p. 25.

44. Silveira AC, Dias JCP. O controle da transmissão vetorial. Rev Soc Bras Med Trop 44 (Supl.2): 52- 63, 2011.

45. Simpson N, Randall R, Lenton S, Walker S. Audit of neonatal screening programme for phenylketonuria and congenital hypothyroidism. Arch Dis Child Fetal Neonatal Ed 77: 228234, 1997.

46. Siriano LR, Luquetti AO, Avelar JB, Marra NL, Castro AM. Chagas Disease: Increased Parasitemia during Pregnancy Detected by Hemoculture. Am J Trop Med Hyg 84: 569-574, 2011.

47. Spano LC, Gatti J, Nascimento JP, Leite JP. Prevalence of human cytomegalovirus infection in pregnant and non-pregnant women. J Infectology 48: 213-220, 2004.

48. Tookey PA, Cortina-Borja M, Peckhmam CS. Rubella susceptibility among pregnant women in North London, 1996-1999. J Public Health Med 24: 211-216, 2002.

49. Vaz AJ, Guerra EM, Ferratto LCC, Toledo LAS, Azevedo NRS. Sorologia positiva para sífilis, toxoplasmose e doença de Chagas em gestantes de primeira consulta em centros de saúde de área metropolitana, Brasil. Rev Saúde Pública 24: 373-379, 1990.

50. Viellas EF, Domingues RMSM, Dias MABastos, Gama SGN, Theme FMM, Costa JV, Bastos MH, Leal MC. Assistência pré-natal no Brasil. Cad Saúde Pública 30 ( Supl 1): S85-S100, 2014.

51. Zufiarre NG, Hernandez JS, Muñoz S, Marin R, Delgado N, Sáenz MC, Bellido JLM, Rodriguez JAG. Seroprevalencia de anticuerpos frente a Treponema pallidum, Toxoplasma gondii, virus de la rubéola, virus de la hepatitis B y C y VIH en mujeres gestantes. Enfermedades Infecciosas y Microbiología Clínica 22: 512-516, 2004. 